\title{
CENTENÁRIO DE NASCIMENTO DO PROFESSOR EMÉRITO NICOLAU NAZO, COMEMORADO NA FACULDADE DE DIREITO DA UNIVERSIDADE DE SÃO PAULO, AOS 11 DE SETEMBRO DE 1995.
}

\author{
Discurso de Agradecimento da Família Nazo, proferido \\ pela Professora Doutora Georgette Nacarato Nazo.
}

Excelentíssimo Senhor Professor Álvaro Villaça Azevedo, DD Diretor da Faculdade de Direito da Universidade de São Paulo: na pessoa de Vossa Excelência externo nossos agradecimentos aos docentes, aos ex-alunos de meu pai daqui e de outras instituições - e aos funcionários desta Casa dos mais antigos aos mais novos - pela consideração que sempre demonstraram a nossa família; Excelentíssimo Senhor Dr. José de Oliveira Messina, meu Presidente na Diretoria da Academia Paulista de Direito; Excelentíssimo Senhor Dr. Domingos Lerário, meu Presidente na Diretoria da Sociedade Amigos da Marinha - Soamar-SP; Excelentíssima Senhora Dra. Regina Hecht, minha Presidente na Diretoria da União Cívica Feminina de São Paulo; meu estimado amigo e sempre Mestre, agora meu confrade, na Academia Paulista de Direito, Professor Dr. Antonio Chaves; amigos, colegas aqui presentes e aqueles que justificaram suas ausências; caro colega, amigo e irmão, Professor Dr. Rubens Limongi França.

Não preparei um discurso, pois queria fruir este momento especial na companhia de meus filhos Anubis e Áulio e de minha nora Maria Thereza, ouvindo o que Limongi França iria relembrar. Fê-lo com a habitual maestria. Surpreenderam-me, também, as palavras de carinho e respeito com que nosso Diretor Álvaro Villaça iniciou os trabalhos desta sessão, que eu pretendia fosse simples, como simples o foi, o homenageado.

Mas, eu não poderia deixar de comemorar a data de hoje. Era forçoso preservar-se a memória daqueles que deram uma contribuição profunda à cultura do País.

Seria de todo inoportuno descer a outras tantas considerações quanto à vida do homenageado, pois, como meu Patrono na Cadeira n. 55 da Academia Paulista de Direito, que hoje ocupo, tive de fazer seu elogio, perquerindo as raízes 
de nossa família, abordando as inúmeras atividades de paizinho: no jornalismo, nas letras, nas artes, na advocacia e no magistério superior. Todos esses ângulos foram examinados e se encontram na publicação feita na Revista de Direito Civil, Imobiliário, Agrário e Empresarial, no ano de 1988, fascículo n. 45, sob o título: "Nicolau Nazo: o retrato de um humanista"

Somente pela circunstância de alguns dos presentes não terem tido a possibilidade de conhecê-lo mais de perto, nem puderam conviver no recesso de nosso lar, é que farei algumas outras referências.

Como bem salientou Limongi França, havia muita compreensão, alegria e atenção em nossa casa, porque meu pai teve a seu lado, a grande musa, companheira dedicada e incentivadora que foi minha mãe. É impossível falar de um, sem referência ao outro, tal a união e o amor existente entre ambos e aquela cumplicidade própria a um casal.

E faço aqui duas pequenas confissões: da mesma forma como - ainda criança - ficava perturbada com a presença de Tulio Ascarelli, durante largo período, diurturnamente em nossa casa, e que só bem mais tarde compreendi que meu pai fizera a tradução para o vernáculo de algumas obras daquele jurista italiano; outra perturbação maior veio a ocorrer conı os constantes diálogos que paizinho manteve com Limongi França, numa fase em que ele e eu estávamos iniciando nossa vida profissional. De Limongi cheguei a sentir um ciúme bobo, pois eram tantas as atenções para ele, uma vez ser considerado um verdadeiro filhovarão para meu pai o que me causava um certo mal-estar. No entanto, era explicável o posicionamento adotado por meu pai: Limongi era um estudioso do Direito que aspirava ao magistério; eu, estudava, mas queria ser, exclusivamente, uma boa advogada. Sempre amei esta profissão, pois lhe dera prioridade sobre o canto lírico e a música, aos poucos relegados a segundo plano...

Todavia, graças ao mesmo Luiz Eulálio de Bueno Vidigal que trouxera Limongi para lecionar, nesta Faculdade, no início da década de sessenta, afastando-se, posteriormente como ele acabou de dizer - para só retornar bem mais tarde, fui então contratada como assistente de Direito Civil, em 1965, por indicação de Vidigal, à época Diretor da Casa.

E ... a advogada precisou curvar-se ao início de um magistério, a adestrar-se num pós-graduação, teses, compromissos, envolvimentos que não estavam em seus projetos iniciais de ser uma boa profissional do Direito.

Prezados amigos: depois das palavras do orador oficial desta cerimônia, só gostaria de aduzir que Nicolau Nazo, além de ter ministrado 
Economia Social nos cursos do Sesi e do Instituto de Direito Social, onde Limongi foi seu aluno, lecionou na Faculdade de Economia da USP e nos cursos de Jornalismo da "Cásper Líbero", onde foi Vice-Diretor, introduziu e regeu as disciplinas de Técnica da Imprensa e Psicologia Social, numa época em que não se cogitava que a Psicologia viesse, um dia, a ter um curso próprio.

Se meu pai conseguiu, com sacrificios, ultrapassar as dificuldades que todos enfrentamos no dia a dia, e encontrou em minha mãe o apoio amoroso e compreensivo, ambos conseguiram transmitir às filhas e, depois, aos netos, um exemplo inestimável. Eles nos legaram valores, valores morais nem sempre encontradiços nos dias que correm. Ensinaram-nos o respeito à hierarquia, o destemor em assumir responsabilidade, para que se possa ter, ao menos, a sensação do dever cumprido e bem cumprido.

Juntos souberam educar os filhos, iniciando-lhes a alfabetização e Ihes favorecendo oportunidades para o futuro, dando-lhes liberdade de opções. Repetiram, com os netos - numa fase complicada de minha vida o que haviam feito com a primeira geração.

Tenho certeza de que, de onde estiverem, estarão felizes com a cerimônia de hoje. E a maneira de agradecermos - eu e meus filhos a todos que dela participam é pedindo a eles a meu pai e minha mãe que nos abençoem, indistintamente, pelo gesto de solidariedade cristã que a família Nazo recebeu neste plenário. Muito Obrigada. 



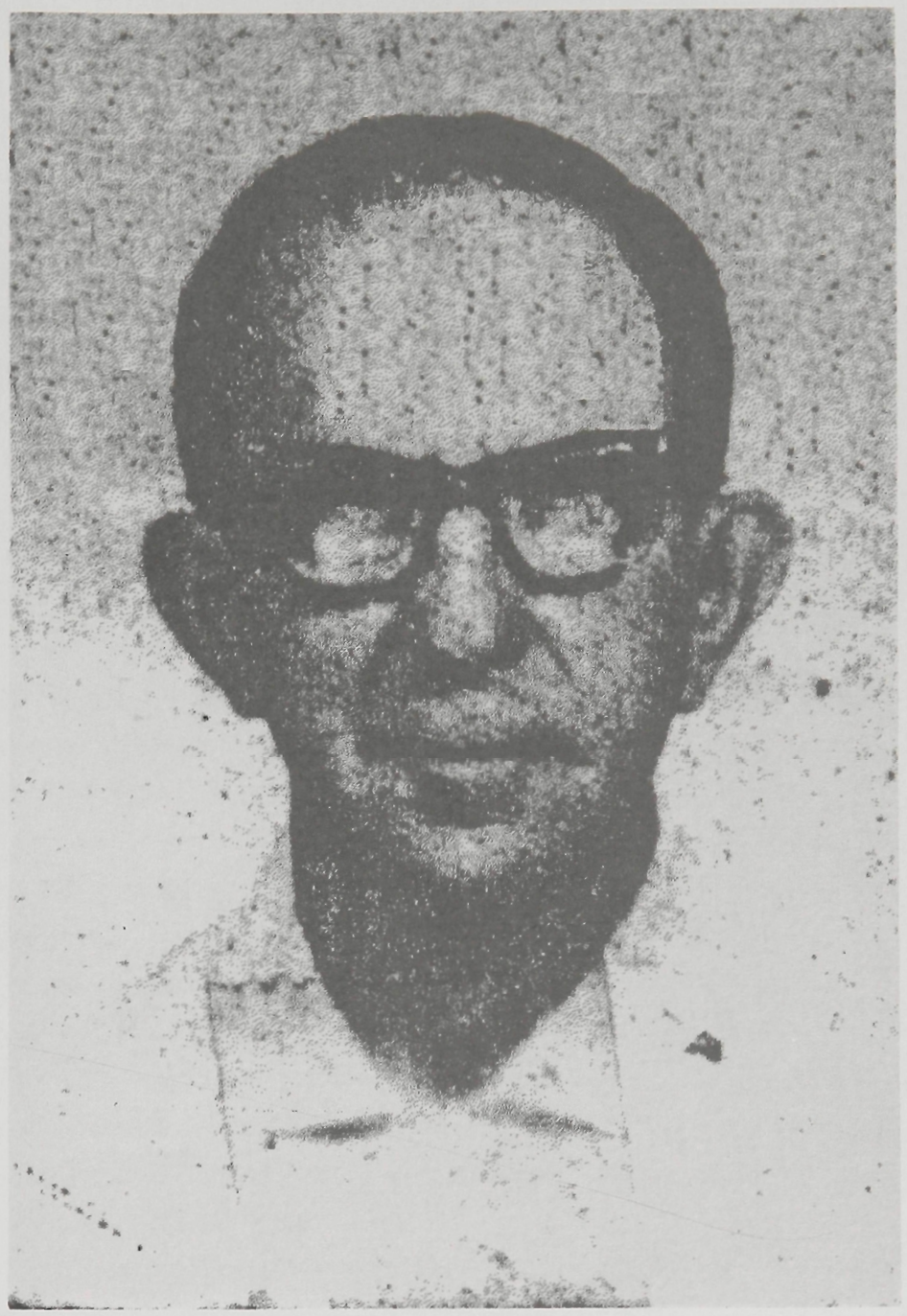

Professor Nicolau Nazo 